\title{
Role of phosphate solubilizing fungi during phosphocompost production and their effect on the growth of tomato (Lycopersicon esculentum L) plants
}

\section{G.Sibi}

Department of Microbiology, Padmashree Institute of Management and Sciences, Bangalore - 560 060, INDIA

E-mail: gsibii@gmail.com

\begin{abstract}
Experiments were conducted to evaluate the effect of phosphate solubilizing fungi (Aspergillus awamori and Trichoderma viride) in phosphocompost preparation along with low grade rock phosphate. Co-inoculation of phosphate-solubilizing fungi significantly increased the nutrient value of the compost that explores high P-solubilizing potential of A.awamori and T. viride which can be exploited for the solubilization of fixed phosphates thereby enhancing soil fertility and plant growth. Rock phosphate application along with phosphate solubilizing fungi increased $69.2 \%$ acid phosphatase and $65 \%$ alkaline phosphatase activity over ordinary compost. With co-inoculation, maximum $\mathrm{P}$ content $(64.3 \%)$ was observed followed by single inoculation with A.awamori (62.2\%). The present findings revealed that phosphate solubilizing fungi can interact positively in promoting nutrient content of compost and plant growth leading to improved yield.
\end{abstract}

Keywords: Aspergillus awamori, Trichoderma viride, Phosphocompost

\section{INTRODUCTION}

Phosphorous is one of the most important plant nutrients which is required for the synthesis of various biomolecules. Because of the negative charge of phosphate ions, they are quickly absorbed after weathering of clays or detritus particles, forming insoluble forms of aluminum, calcium, or iron phosphates, all unavailable to plants. Fungi and bacteria have the ability to solubilize these compounds (Illmer, 1995). Although several mechanisms may be involved, the main one is through the production of organic acids (Nahas, 1996). It is noticed that, plants cannot utilize phosphorous directly and only $30 \%$ of the soluble form of phosphorous is made available to plants. Phosphorous is generally fixed in the soil in an insoluble form as calcium phosphate, aluminium phosphate and ferrous phosphate. Several bacteria and fungi are reported to be efficient in solubilizing these phosphates (Arora and Gaur, 1979).

It is estimated that about 260 million tonnes (Mt) of RP deposits are available in India (FAI, 2002) and only a fraction of it (about 5.27 Mt) meets the specification of the fertilizer industry because of their low $\mathrm{P}$ content (lowgrade). Phosphate solubilizing microorganisms produce low molecular mass organic acids (Deubel and Merbach, 2005), which attack the phosphate structure and transforms phosphorous from non-utilizable to the utilizable form for the plants (Ivanova et al., 2006). Recently, emphasis has been made to the possibility of greater utilization of low cost, indigenously available rock phosphate resources and making it more efficient by the addition of phosphate solubilizing microorganisms. In order to upgrade nutrient content of the compost, the use of rock phosphate and phosphate solubilizing microorganisms has been documented (Pazhanivelan et al., 2006; Biswas and Narayanasamy, 2006). Phosphate solubilizing microorganisms (PSM) are able to improve the phosphorous nutrition and stimulate the plant growth. Solubilization is due to the secretion of organic acids by microorganisms which reduces the $\mathrm{pH}$ or by complexing cation that is bound to phosphorous, in turn decrease the particle size. However, the role of organic acids and low $\mathrm{pH}$, holds a major role to play in phosphate availability in vitro and in vivo (Kim et al., 1997). Phosphate solubilizing bacteria (PSB) are known to mobilize insoluble phosphorous to soluble forms through enzymatic reactions (Gaur and Gaind, 1983). The productiveness of rhizosphere for phosphate solubilizing microorganisms may be due to root exudates which contain aminoacids, carbohydrates, organic acids and growth promoting substances (Gaur et al., 1973).

The present study was carried out with the objective of substituting costly phosphate fertilizers by production and use of phosphocompost enriched with indigenously available low grade rock phosphate along with efficient phosphate solubilizers.

\section{MATERIALS AND METHODS}

Crop residues such as leaves, stalks, twigs and seed pods were collected from farmers' field and added layer by layer in cement pits of $0.9 \times 0.9 \times 0.6 \mathrm{~m}^{2}$ size. The thickness of each layer was 3-4 cm. cow dung slurry at the rate of 
25 per cent of total dry weight material was added as a starter material. For enrichment of compost, rock phosphate (RP) was added at the rate of 5 per cent $(1 \%$ $\mathrm{P}_{2} \mathrm{O}_{5}$ ) of total weight of raw materials. Moisture content was maintained at about $60 \%$ and the pits were covered with a thin layer of soil in order to raise the temperature. The temperature of the heap was monitored every day. Potato dextrose agar slant cultures of Aspergillus awamori and Trichoderma viride were inoculated into potato dextrose broth and incubated at room temperature till the O.D value reaches 2.0 at $600 \mathrm{~nm}$ for the enrichment purpose.

After 90 days, the matured compost was enriched by the addition of phosphate solubilizers (A.awamori and T.viride) for the production of phosphocompost with various combinations and the treatments were,

$\mathrm{T}_{1}$ - Phosphocompost + A.awamori

$\mathrm{T}_{2}$ - Phosphocompost $+\mathrm{T}$. viride

$\mathrm{T}_{3}$ - Phosphocompost + A.awamori + T.viride

Control - Farm yard manure alone

Representative samples of each treatment were collected from top, middle and lower layer after 90 days of decomposition. Samples collected from different layers were mixed, air dried, grinded and sieved for analysis. The samples were analyzed for organic carbon by combustion method and total nitrogen by Kjeldhal method (Black, 1982), total P by vanadomolybdo phosphoric yellow colour method (Jackson, 1967). Calcium and magnesium content were estimated by EDTA Titration method (Piper, 1966) and potassium was estimated by the method as outlined by Toth and Prince (1949). Phosphatase content of the phosphocompost samples was determined by following the method of Evazi and Tabatabai (1977).

Field experiments were conducted in replicated randomized block design with five replications to evaluate the direct effect of various combinations of compost. Tomato seedlings were transplanted on flat beds, since it prevents the fruit appearing on the lower branches from making direct contact with the soil. Tomato plants were harvested at different intervals (45, 60 and 90 days) and the growth parameters were recorded.

Statistical analysis were done using Duncan's new multiple range test to compare means and simple correlation coefficient was performed to examine the relationships between individual properties.

\section{RESULTS AND DISCUSSION}

Natural phosphate rocks have been recognized as a valuable alternative for $\mathrm{P}$ fertilizers. In recent years, the possibility of practical use of rock phosphates as fertilizers has received significant interest. Conventionally, rock phosphate is chemically processed by reacting with sulphuric acid or phosphoric acid into soluble phosphate fertilizer. The process increases fertilizer cost and makes the environment worse (Reddy et al., 2002; Chuang et al., 2007; Xiao et al., 2008). An alternative has been the use of microorganisms with the capability to solubilize rock phosphate and release soluble phosphorous through the production of organic acids, chelating oxo acids from sugars, reduction of $\mathrm{pH}$ and production of enzymes. Several reports have indicated that some microorganisms are capable of solubilizing insoluble rock phosphate and releasing soluble phosphate. Among the microbes Aspergillus awamori has been reported as an efficient phosphate solubilizer (Biswas and Narayanasamy, 2006; Zaidi and Khan, 2006; Geetika and Dev, 2009).

Table 1 shows the results of nutrient content of phosphocompost enriched with phosphate solubilizers in various combinations. Optimum organic carbon content $(28.56 \%)$ was found in $\mathrm{T}_{3}$ treatment followed by single inoculation with A.awamori $\left(\mathrm{T}_{1}\right)$. Perusal of the results revealed that application of phosphocompost sustained higher organic carbon.

A significant difference in the total nitrogen content was observed in co-inoculation treatment $\left(\mathrm{T}_{3}\right)$ when compare to compost without rock phosphate and phosphate solubilizers (control). The apparent increase in total nitrogen content in compost is not only due to enrichment but also due to the reduction in weight because of decomposition (Jeevan Rao et al., 2008).

EDTA titration method of phosphocompost revealed that considerable increase of calcium and magnesium content in phosphocompost than the ordinary compost. Double inoculation $\left(\mathrm{T}_{3}\right)$ has recorded highest calcium and magnesium percent (1.484 and 0.289) and single inoculation with T.viride showed second highest magnesium percent (1.080) which may be due to the mineralization of nutrients by the micro organisms. The total potassium content was ranged from 0.856 to 1.690

Table 1. Nutrient content of the phosphocompost enriched with bio-inoculants.

\begin{tabular}{|c|c|c|c|c|c|c|c|c|}
\hline \multirow[t]{2}{*}{ Treatments } & \multicolumn{6}{|c|}{ Percent } & \multicolumn{2}{|c|}{ Phosphatase $\mu \mathrm{g} / \mathrm{g}$} \\
\hline & C & $\mathrm{N}$ & $\mathrm{Ca}$ & $\mathrm{Mg}$ & $\mathrm{K}$ & $\mathrm{P}$ & Acid & Alkaline \\
\hline $\mathrm{T}_{1}$ & 29.47 & 0.425 & 1.205 & 0.210 & 1.026 & 0.389 & 0.370 & 0.390 \\
\hline $\mathrm{T}_{2}$ & 29.29 & 0.411 & 1.194 & 0.221 & 1.080 & 0.361 & 0.290 & 0.320 \\
\hline $\mathrm{T}_{3}$ & 28.56 & 0.540 & 1.484 & 0.289 & 1.690 & 0.412 & 0.390 & 0.400 \\
\hline Control & 37.52 & 0.364 & 0.902 & 0.114 & 0.856 & 0.147 & 0.120 & 0.140 \\
\hline
\end{tabular}


Table 2. Growth parameters of tomato plants

\begin{tabular}{|c|c|c|c|c|c|c|c|c|c|}
\hline \multirow[b]{2}{*}{ Treatments } & \multicolumn{3}{|c|}{45 Days } & \multicolumn{3}{|c|}{60 days } & \multicolumn{3}{|c|}{90 Days } \\
\hline & $\begin{array}{c}\text { Root } \\
\mathrm{cm}\end{array}$ & $\begin{array}{c}\text { Shoot } \\
\mathrm{cm}\end{array}$ & $\begin{array}{c}\text { Drywt } \\
\mathrm{g}\end{array}$ & $\begin{array}{c}\text { Root } \\
\mathrm{cm}\end{array}$ & $\begin{array}{c}\text { Shoot } \\
\mathrm{cm}\end{array}$ & $\begin{array}{c}\text { Drywt } \\
\mathrm{g}\end{array}$ & $\begin{array}{c}\text { Root } \\
\mathrm{cm}\end{array}$ & $\begin{array}{c}\text { Shoot } \\
\mathrm{cm}\end{array}$ & $\begin{array}{c}\text { Drywt } \\
\mathrm{g}\end{array}$ \\
\hline $\mathrm{T}_{1}$ & 26 & 74 & 46.0 & 39 & 98 & 57.0 & 49 & 118 & 72.5 \\
\hline$T_{2}$ & 28 & 71 & 31.0 & 38 & 90 & 39.5 & 43 & 108 & 59.5 \\
\hline$T_{3}$ & 26 & 89 & 50.6 & 43 & 104 & 65.0 & 52 & 128 & 78.0 \\
\hline Control & 19 & 65 & 26.5 & 31 & 80 & 33.6 & 36 & 96 & 50.5 \\
\hline
\end{tabular}

$\mathrm{T}_{1}$ - Phosphocompost + A. awamori, $\mathrm{T}_{2}$ - Phosphocompost + T. viride, $\mathrm{T}_{3}$ - Phosphocompost $+\mathrm{A}$. awamori $+\mathrm{T}$. viride, Control - Farm yard manure alone

and the maximum was observed in $\mathrm{T}_{3}$ treatment followed by $\mathrm{T}_{2}(1.080)$.

Results showed that Rock Phosphate charged compost enhanced the content of total $\mathrm{P}$ in the final product when compared to untreated compost and this may be attributed due to greater mobilization of $\mathrm{P}$ from Rock Phosphate. Co-inoculation with A. awamori and T.viride showed highest phosphorous content (0.412 percent) and there was a slight variation between $T_{1}$ and $T_{2}$. Increase in the amount of phosphorus in the compost with the progress of time and inoculation with phosphate solubilizing fungi was reported by Tripathi and Bhardwaj (2004).

Both acid and alkaline phosphatase activity were found higher in $\mathrm{T}_{3}$ treatment $(0.390$ and $0.400 \mu \mathrm{g} / \mathrm{g})$ followed by $\mathrm{T}_{1}$ treatment. Plants inoculated with phosphate solubilizing fungi significantly increased the phosphatase activity of the compost and is in accordance with the reports of Goyal and Mishra (1983). The result clearly indicates that, out of many combinations, co-inoculation system provides optimum condition for the acid and alkaline phosphatase activity. The role of mineralizing enzymes is important in composting process because their activity is one of the deciding factor for regulating concentration of available nutrients per unit weight of compost and thereby the varying quality of compost. In the present study, the activity of acid and alkaline phosphatase was significantly high in phosphocomposting than ordinary composting system. Phosphorus is a constituent of Nucleic acids, phospholipids and coenzymes. It is also a constituent of ATP, ADP, Pi, phosphorylated sugars and phosphorylated organic acids. In the light of this information, the rock phosphate added during phosphocomposting might have increased the biological activity which was reflected in increased activity of mineralizing enzymes. Similar results were found in the studies by Ragavedra Rao et al. (2009).

Tomato plants grown under $\mathrm{T}_{3}$ treatment exhibited higher growth parameters (Table 2) followed by $\mathrm{T}_{1}$. Coinoculation has influenced the dry weight of the plants in all intervals and a significant increase in plant dry weight was observed in single inoculation with A.awamori $\left(\mathrm{T}_{1}\right)$. Lowest growth parameters were recorded in control plants which described that inoculation of phosphate solubilizers to the compost has increased the nutrient content of the compost and thus influenced the growth parameters of tomato plants.

Many bacteria (Rodriguez and Fraga, 1999) and fungi (Whitelaw, 2000) are able to improve plant growth by solubilizing sparingly soluble inorganic and organic phosphates in the soil. Production and release of organic acids is an important mechanism involved in inorganic $P$ solubilization (Richardson, 2001). Phosphate solubilizing fungi synergistically solubilized rock phosphate which was added into the compost and make them much more available for uptake by plant roots. The use of compost along with phosphate solubilizers and low grade rock phosphate substitutes the phosphatic fertilizers and increases the product yield in terms of qualitative and quantitative manner.

In conclusion, this study revealed that the co-inoculation of A.awamori and T.viride along with rock phosphate has improved nutrient status of the phosphocompost. Moreover this combination brought about significant increase in the growth parameters of tomato plants, suggesting their applicability for crop improvement which would be the future trends of bio-fertilizer application for sustainable crop production.

\section{REFERENCES}

Arora, D. and Gaur, A. C. (1979). Microbial solubilization of different inorganic phosphates. Ind. J . Expt. Biol., 17: 12581261.

Biswas, D. R. and Narayanasamy, G. (2006). Rock phosphate enriched compost: An approach to improve low grade Indian rock phosphate. Bioresource Technol., 97: 2243-2251.

Black, C. A. (1982). Methods of Soil Analysis. Part-II. American Society of Agronomy, Inc., Madison, Wisconsin. USA.

Chuang, C. C., Kuo, Y. L., Chao, C. C. and Chao, W. L. (2007). Solubilization of inorganic phosphates and plant growth promotion by Aspergillus niger. Biol. Fert. Soils., 43: 575584.

Deubel, A. and Merbach, W. (2005). Influence of Microorganisms on Phosphorus Bioavailability in Soils. In 
: Buscot, F. and A. Varma (Eds.). Microorganisms in Soils: Roles in G enesis and Functions, pp : 177-91. Springer-Verlag, Berlin-Heidelberg, Germany.

Evazi, Z. and Tabatabai, M. A. (1977). Phosphatase in soils. Soil Biol. Biochem., 9: 167-172.

FAI (2002). The Fertiliser Association of India, New Delhi. Fertiliser Statistics 2001-2002 I, pp. 39-47.

Gaur, A. C., Madan, M. and Ostwal, K. P. (1973). Solubilization of phosphatic compounds by native microflora of rock phosphate. Ind. J. Expt. Biol., 11: 427-429.

Gaur, A. C. and Gaind, S. (1983). Microbial solubilization of insoluble phosphates with particular reference to iron and aluminium phosphate. Sci. Cult., 49: 110-112.

Gaur, K. Y., Mc Donald, G. A. and Jordan, D. (1997). Solubilization of hydroxyl apatite by Enterobacter agglomerans and cloned Escherichia coli in culture medium. Biol. Fertil. Soils., 24: 347-352.

Geetika, B. and Dev, S. P. (2009). Field evaluation of nitrogen enriched phosphocompost prepared from green biomass of Lantana camara in wheat. Indian J. Ecol., 36(1):39-44.

Goyal, S. and Mishra, M. M. (1983). The phosphatase activity and release of phosphorous during composting with fungal inoculants and in the presence of phosphate. Agri. Wastes., 7: 151-157.

Illmer, P. (1995). Solubilization of hardly-soluble $\mathrm{AlPO}_{4}$ with P-solubilizing microorganism. Soil Biol. Biochem., 27: 265270.

Ivanova, I., Bojinova, D. and Nedialkova, K. (2006). Rock phosphate solubilization by soil bacteria. J. U niv. Chem. Technol. and M etallurgy, 41(3): 297-302.

Jackson, M.L. (1967). Soil chemical analysis. Prentice Hall of India (P) Ltd., New Delhi.

Jeevan Rao, K., Rama Lakshmi, S. and Sreenivasa Raju, A. (2008). Evaluation of manurial value of urban and agricultural waste composts, J ournal of the Indian Society of Soil Science, 56 (3): 295-299.

Kim, K. Y., Jordan, D. and McDonald, G. A. (1997). Solubilization of hydroxyapatite by and cloned in culture medium. Biol F ertility Soils, 24 : 347-352.

Nahas, E. (1996). Factors determining rock phosphate solubilization by microorganisms isolated from soil. W. J . Microbiol. Biotechnol., 12: 567-572

Pazhanivelan, S., Amanullah, M. M. Vaiyapuri, K., Rahale, C.S., Sathyamoorthi, K. and Alagesan, A. (2006). Effect of rock phosphate incubated with FYM on nutrient uptake and yield of lowland rice. Res. J. Agric. Biol. Sci., 2(6): 365368.

Piper, C.S. (1966). Soil and plant analysis. Hans publications, Bombay, India.

Raghavendra Rao, B., Radhakrishna, D. and Shantha, S. L. (2009). Activity of mineralizing enzymes during composting of urban solid waste. E. J. E. A. F. Che., 8 (9): 799-805.

Reddy, M.S., Kumar, S., Babita, K. and Reddy, M.S. (2002). Biosolubilization of poorly soluble rock phosphates by Aspergillus tubingensis and Aspergillus niger. Bioresour. Technol., 84: 187-189.

Richardson, A. E. (2001). Prospects for using soil microorganisms to improve the acquisition of phosphorus by plants. Aust. J. Plant Physiol., 28: 897-906.

Rodriguez, H. and Fraga, R. (1999). Phosphate solubilizing bacteria and their role in plant growth promotion. Biotech. Adv., 17: 319-339.

Toth, S. J. and Prince, A. L. (1949). Potassium determination in plant digests by flame photometer. Soil, Plant and Water Analysis by P.C. Jaiswal. pp. 275-279.

Tripathi, G. and Bhardwaj, P. (2004). Comparative studies on biomass production, life cycles and composting efficiency of Eisenia fetida (Savigny) and Lampito mauritii (Kinberg). Biores. Technol., 94: 275-283.

Whitelaw, M. A. (2000). Growth promotion of plants inoculated with phosphate-solubilizing fungi. Adv. Agron., 69: 99-151.

Xiao, C. Q., Chi, R. A., Huang, X. H., Zhang, W. X., Qiu, G. Z. and Wang, D. Z. (2008). Optimization for rock phosphate solubilization by phosphate solubilizing fungi isolated from phosphate mines. Ecol. Eng., 33: 187-193.

Zaidi, A. and Khan, M. S. (2006). Co-inoculation effects of phosphate solubilizing microorganisms and Glomus fasciculatum on Green Gram-Bradyrhizobium symbiosis. Turk. J. Agric. F or., 30: 223-230. 